\title{
Kleines Sach- und Wortregister
}

Archaeologia Homerica X

Aristarch s. Homertext

Aristoteles s. Homerbild und

Kulturentwicklung

Bremer Stadtmusikanten 188ff.

Bronzezeit s. Griechenland

Double deixis in Homeric Speech: hóde und hóutos 63ff.

Etymologie zu pérthō und eáphthe $119 f$.

Griechenland und Kleinasien in der Spätbronzezeit

Ahhijawa 149

Hethiter, Hetthitisch $147 f$.

Homer 170

Kolb gegen Korfmann 143

Schliemann H. $143 f$.

Spätbronzezeit $141 \mathrm{ff}$.

Troia 141ff.

Schrott R. widerlegt 142

Tawagalawa-Brief 166

Homerbild, Homerdeutung 263ff.

Aristoteles 269

Arten von Handeln 300

Geschichtszeit 280

Handlung bei Aristoteles 292

Handlung bei Homer 292

Ilias gemacht? 297

Innere Vorgänge 288

Menis-Handlung 282

Motivation des Handelns 279

Poetische Verfahrensweise 280

Homerische Hymnen $1 \mathrm{ff}$.

als Opfergabe 23
Homertext in der Antike 239ff.

Aristarch 193ff., 245

Didymos 244

Zenodots Homertext 248

Ilias diachronica $335 \mathrm{ff}$.

Analyse des Xi 335

Homer 336

metrische Entwicklung 335

Kulturentwicklung in Europa

Aristoteles 100

Athen 99f.

Deutsche Klassik 109

Homerbestimmtheit 89, 102,

115

Hom.-Diskurs in Ostionien 91

Ionische Wende, Milet 96

Livius Andronicus 104

Moderne Literatur 115

Troia-Literatur im MA 105

Xenophanes von Kolophon $97 \mathrm{f}$.

Lexikon des frühgriech.

Epos (LfgrE) V

Geschichte LfgrE 253ff.

Gründung durch Snell 253

Krise ab 1976255

Latacz J. 89

Parry ante portas 259

Snells Thema 258

Međedović A.

,jugoslawischer Homer ${ }^{6}$ 27ff.

Lord A. $29 \mathrm{ff}$.

oral theory 30

Parry M. 27ff. 
Odysseus bei den Phäaken

Apologoi des Odysseus 217, 220

Heimkehrerhandlung $215 \mathrm{ff}$.

Kyklopen 227

Nostos 215

Poseidon 226

xénos 223

Patroklos und Phoinix 181ff.

Patroklos, s. Wörter

Präpositionalausdrücke,

Lokalpartikeln bei Hom. 45ff.

im Vedischen 48 zur Verwendung mit Gen. 54ff.

Tmesis 45

Scholia omerici

Glosse dialettali 123ff.

Cipro 129

Creta 131

Theory of mind 319ff.

$\bar{e} 319 \mathrm{ff}$.

Snell B. V, X, 253, 263, 319

Wörter im Kontext 85ff.

Sprecherpersönlichkeit 85

,naming Patroclus‘ 86 